\title{
Influence of Different Doses of Levofloxacin on Antioxidant Defense Systems and Markers of Renal and Hepatic Dysfunctions in Rats
}

\author{
Ebenezer Tunde Olayinka, Ayokanmi Ore, and Olaniyi Solomon Ola \\ Biochemistry Unit, Department of Chemical Sciences, Ajayi Crowther University, PMB 1066, Oyo, Oyo State 211213, Nigeria \\ Correspondence should be addressed to Ebenezer Tunde Olayinka; et.olayinka@acu.edu.ng
}

Received 22 September 2014; Revised 9 December 2014; Accepted 9 December 2014

Academic Editor: Arezoo Campbell

Copyright (C) 2015 Ebenezer Tunde Olayinka et al. This is an open access article distributed under the Creative Commons Attribution License, which permits unrestricted use, distribution, and reproduction in any medium, provided the original work is properly cited.

\begin{abstract}
Levofloxacin (LFX) is a broad spectrum fluoroquinolone antibiotic used in the treatment of infections such as pneumonia, chronic bronchitis, and sinusitis. The present study assessed the likely toxic effect of LFX on hepatic and renal tissues in rats. Twenty male Wistar rats were randomly divided into four treatment groups: A: control, B: $5 \mathrm{mg} / \mathrm{kg}$ bw LFX (half therapeutic dose), C: $10 \mathrm{mg} / \mathrm{kg}$ bw LFX (therapeutic dose), and D: $20 \mathrm{mg} / \mathrm{kg}$ bw LFX (double therapeutic dose). After seven days of administration, result indicated significant $(P<0.05)$ increase in plasma ALT, AST, and ALP activities in the treated groups compared to control. Also, there was a significant increase in plasma creatinine, urea, and total bilirubin in the treated groups relative to control. Plasma total cholesterol, HDL-cholesterol, LDL-cholesterol, and triglycerides also increased significantly in the treated groups relative to control. Also, hepatic MDA level increased significantly in all the treated groups. However, hepatic SOD, catalase, and GST activities were significantly reduced in the LFX-treated animals. Moreover, GSH and ascorbic acid levels were significantly decreased in the LFX-treated groups relative to control. In conclusion, three doses of levofloxacin depleted antioxidant defense system and induced oxidative stress and hepatic and renal dysfunctions in rats.
\end{abstract}

\section{Introduction}

Levofloxacin (LFX) belongs to fluoroquinolone antimicrobial agents that have broad spectrum bactericidal effect against both Gram-positive and Gram-negative bacteria $[1,2]$. It is a chosen drug with better efficacy in the treatment of typhoid fever especially when compared with other members of the same family such as ciprofloxacin [3]. Its usage has been extended to treatment of varieties of infections in adults such as sinus infections, bronchitis, pneumonia, and genitourinary infections including both complicated and uncomplicated urinary tract infections $[4,5]$.

LFX is a chiral fluorinated carboxyquinolone (Figure 1) with fluorine at position 9, a pure (-)-S-enantiomer of the racemic drug substance ofloxacin [6]. It has lowest phototoxic potential $[7,8]$. The reduced risk of photosensitivity is due to the fluorine at position 9 rather than position 8 of quinolone nucleus that is related to the risk of phototoxicity as it is found in lomefloxacin and sparfloxacin [9]. LFX, being a fluoroquinolone, primarily targets bacterial topoisomerase IV and DNA gyrase in Gram-positive and Gram-negative bacteria, respectively, as its mechanism of action [10]. LFX undergoes limited metabolism and is primarily excreted unchanged [11, 12]. Two metabolites, desmethyl-levofloxacin $\mathrm{N}$-oxide, have been identified in humans and they contribute minimal pharmacological activities [13].

Generally, fluoroquinolone has been shown to be associated with certain adverse effects like Juvenile joint toxicity, gastrointestinal discomfort, adverse central nervous system effect, and cutaneous reaction such as phototoxicity $[14,15]$. However, LFX had been reported to have low potential to cause adverse hepatobiliary reaction [16]. Despite its clinical acceptability and usage, there are little reports on its effect on antioxidant defense system. Several in vivo and in vitro studies have related phototoxicity of fluoroquinolone to the generation of reactive oxygen species (ROS) such as superoxide anion, hydrogen peroxide, and hydroxyl radical $[17,18]$. 
<smiles>C[C@@H]1COc2c(N3CCNCC3)c(F)cc3c(=O)c(C(=O)O)cn1c23</smiles>

FIGURE 1: Structure of levofloxacin.

These ROS caused severe damage to macromolecules, tissues, and organs through the process of lipid peroxidation (LPO), protein modification, and DNA damage $[19,20]$. Oxidative stress results when these ROS overwhelm the antioxidant system [21]. Oxidative stress has been linked with pathogenesis of some disease conditions such as cardiovascular disorders, aging, cancer, and neurodegenerative disease [22, 23].

Cell protects itself from effect of ROS by the action of nonenzymatic antioxidants (Vitamins $\mathrm{A}, \mathrm{E}$, and $\mathrm{C}$ and reduced glutathione $\mathrm{GSH}$ ) and enzymatic antioxidant such as superoxide dismutase, catalase, and glutathione peroxidase (GPX) [24]. In the present study, we investigate the toxicity of levofloxacin using the status of antioxidant defense system, markers of kidney and renal damage, and some biochemical indices in rats.

\section{Materials and Methods}

2.1. Chemicals and Reagents. Levofloxacin (Devox) is a product of Waves-Biotech Pvt. Ltd., New Delhi, India. Glutathione (GSH), 1-chloro-2,4-dinitrobenzene (CDNB), 5, 5' dithio-bis-2-nitrobenzoic acid (DTNB), thiobarbituric acid (TBA), epinephrine, and hydrogen peroxide were purchased from Sigma chemical company (London, UK). Alkaline phosphatase (ALP), alanine amino transferase (ALT), aspartate aminotransferase (AST), gamma glutamyl transferase (GGT), urea, creatinine, bilirubin, total cholesterol, HDLcholesterol, LDL-cholesterol, and triglycerides assay kits were products of Randox Laboratories Ltd. (Antrim, UK). All other chemicals and reagents were of analytical grade and of highest purity.

2.2. Animals and Treatments. Male rats (Wistar strain) weighing between 180 and $220 \mathrm{~g}$ were used in this study. The rats were bred and housed in the animal house of the Department of Chemical Sciences, Ajayi Crowther University, Oyo, Nigeria. They were kept in wire meshed cages at room temperature and under controlled light cycle (12 hr light: dark). They were fed with commercial rat chow (Ladokun feeds, Ibadan, Nigeria) and water ad libitum. The experimental animals were handled and used in accordance with the international guide for the care and use of laboratory animals (National Research Council) [25].
2.3. Experimental Design. Twenty male albino rats (Wistar strain) were randomly divided into four groups of 5 rats each. Group 1 animals were used as control and received distilled water. Group 2 animals were treated with LFX-1 (equivalent to $5 \mathrm{mg} / \mathrm{kg}$ body weight of levofloxacin). Group 3 animals were treated with LFX-2 (equivalent to $10 \mathrm{mg} / \mathrm{kg}$ body weight of levofloxacin), while Group 4 animals were treated with LFX3 (equivalent to $20 \mathrm{mg} / \mathrm{kg}$ body weight of levofloxacin). $1 \mathrm{~mL}$ of each of the prepared LFX solutions was administered orally to the animals in the different groups using an oral cannula once daily for a period of seven days (the normal duration of therapy in humans). The animals were sacrificed 24 hours after the last treatment.

2.4. Collection of Blood Samples for Plasma Preparation. Blood was collected from the retroorbital plexus of the animals into heparinized tubes, and the rats were sacrificed by cervical dislocation. Plasma was prepared by centrifuging blood samples for ten minutes at $3000 \mathrm{rpm}$ in a cencom bench centrifuge. The clear supernatant was used for the estimation of urea, creatinine, bilirubin, lipid profiles, and enzymes.

2.5. Preparation of Cytosolic Fractions. The liver, excised from rat, blotted of blood stains, and rinsed in $1.15 \% \mathrm{KCl}$, was homogenized in 4 volumes of ice-cold $0.01 \mathrm{M}$ potassium phosphate buffer ( $\mathrm{pH}$ 7.4). The homogenates were centrifuged at $12,500 \mathrm{~g}$ in an Eppendorf (UK) refrigerated centrifuge for $15 \mathrm{~min}$ at $4^{\circ} \mathrm{C}$ and the supernatants, termed as the postmitochondrial fractions (PMF), were used for enzyme assays.

2.6. Renal and Liver Functions Test. Plasma creatinine, urea, and bilirubin determination was done using Randox diagnostic kits. Methods for creatinine assays are based on colorimetric alkaline picrate methods [26] with creatinine-picrate complex measured at $492 \mathrm{~nm}$. The urea determination method was based on the Fearon reaction [27], with the Diazine chromogen formed being absorbed strongly at $540 \mathrm{~nm}$. The dimethyl sulphoxide method by Tietz et al. [27] was used for bilirubin determination. The dimethyl sulphoxide forms a coloured compound with maximum absorption at $550 \mathrm{~nm}$.

2.7. Determination of Plasma AST, ALT, ALP, and GGT Activities. Plasma AST, ALT, ALP, and GGT activities were determined using Randox diagnostic kits. Determination of AST and ALT activities was based on the principle described by Tietz et al. [27]. AST was measured by monitoring the concentration of oxaloacetate hydrazone formed with 2,4dinitrophenylhydrazine at $546 \mathrm{~nm}$ and ALT was measured by monitoring the concentration of pyruvate hydrazone formed with 2,4-dinitrophenylhydrazine at $546 \mathrm{~nm}$. ALP was determined in accordance with the principles of Tietz [28]. The p-nitrophenol formed by the hydrolysis of $\mathrm{p}$-Nitrophenyl phosphate confers yellowish colour on the reaction mixture and its intensity can be monitored at $405 \mathrm{~nm}$ to give a measure of enzyme activity. GGT activity was measured based on a modification of the method described by Hørder et al. [29] using Abbott diagnostic kit. 
TABLE 1: Effect of levofloxacin treatments on plasma creatinine, urea, and bilirubin levels in rats.

\begin{tabular}{lccr}
\hline Treatment & Creatinine $(\mathrm{mg} / \mathrm{dL})$ & Urea $(\mathrm{mg} / \mathrm{dL})$ & Bilirubin $(\mathrm{mg} / \mathrm{dL})$ \\
\hline Control & $0.72 \pm 0.02$ & $36 \pm 0.82$ & $0.24 \pm 0.02$ \\
LFX-1 & $0.80 \pm 0.01(19 \%)^{*}$ & $47 \pm 0.5(31 \%)^{*}$ & $0.48 \pm 0.03(100 \%)^{*}$ \\
LFX-2 & $0.88 \pm 0.03(22 \%)^{*}$ & $52 \pm 1.29(44 \%)^{*}$ & $0.56 \pm 0.03(133 \%)^{*}$ \\
LFX-3 & $0.91 \pm 0.00(26 \%)^{*}$ & $55 \pm 0.58(53 \%)^{*}$ & $0.66 \pm 0.03(175 \%)^{*}$ \\
\hline
\end{tabular}

The values are means \pm SD for five rats in each group. ${ }^{*}$ Significantly different from the control $P<0.05$. Values in parenthesis represent percentage (\%) of the increase.

TABLE 2: Effects of levofloxacin treatments on plasma alkaline phosphatase (ALP), alanine aminotransferase (ALT), and aspartate aminotransferase (AST) activities in rats.

\begin{tabular}{lccc}
\hline Treatment & ALP $(\mathrm{U} / \mathrm{L})$ & ALT $(\mathrm{U} / \mathrm{L})$ & AST $(\mathrm{U} / \mathrm{L})$ \\
\hline Control & $187 \pm 2.44$ & $33 \pm 3.30$ & $60 \pm 3.09$ \\
LFX-1 & $220.8 \pm 2.56(18 \%)^{*}$ & $48 \pm 4.92(45 \%)^{*}$ & $82 \pm 1.25(37 \%)^{*}$ \\
LFX-2 & $256 \pm 4.34(37 \%)^{*}$ & $52 \pm 2.28(58 \%)^{*}$ & $86 \pm 1.50(43 \%)^{*}$ \\
LFX-3 & $276 \pm 2.51(48 \%)^{*}$ & $55 \pm 2.879(67 \%)^{*}$ & $94 \pm 2.7(57 \%)^{*}$ \\
\hline
\end{tabular}

The values are means \pm SD for five rats in each group. ${ }^{*}$ Significantly different from the control $P<0.05$. Values in parenthesis represent percentage $(\%)$ of the increase.

2.8. Determination of Plasma Lipid Profiles. The plasma total cholesterol, HDL-cholesterol, LDL-cholesterol, and triglycerides were determined using Randox diagnostic kits and the determination was based on CHOD-PAD enzymatic colorimetric method of Trinder [30].

2.9. Assay of Nonenzymatic Antioxidants and Lipid Peroxidation. Hepatic vitamin $\mathrm{C}$ was determined according to the method of Erel et al. [31] using dinitro phenyl hydrazine (DNPH), while hepatic glutathione was determined according to the method of Jollow et al. [32]. The chromophoric product resulting from the reaction of Ellman's reagent with the reduced glutathione, 2-nitro-5-thiobenzoic acid, possesses a molar absorption at $412 \mathrm{~nm}$ which was read in a spectrophotometer. Reduced GSH is proportional to the absorbance at $412 \mathrm{~nm}$. The extent of lipid peroxidation (LPO) was estimated by the method of Varshney and Kale [33]; the method involved the reaction between malondialdehyde (MDA) and thiobarbituric acid to yield a stable pink chromophore with maximum absorption at $532 \mathrm{~nm}$.

2.10. Determination of Antioxidant Enzymes. The procedure of Misra and Fridovich [34] as described by Magwere et al. [35] was used for the determination of hepatic superoxide dismutase (SOD) activity by measuring the inhibition of autooxidation of epinephrine at $\mathrm{pH} 10.2$ and $30^{\circ} \mathrm{C}$. SOD activity was expressed in $\mathrm{U} / \mathrm{mg}$ protein. Hepatic catalase activity was determined according to the method of Sinha [36] by measuring the reduction of dichromate in acetic acid to chromic acetate at $570 \mathrm{~nm}$. Catalase activity was expressed as $\mu \mathrm{mol} \mathrm{H}_{2} \mathrm{O}_{2}$ consumed $/ \mathrm{min} / \mathrm{mg}$ protein. Hepatic glutathione S-transferase (GST) activity was determined by the method described by Habig et al. [37] using 1-chloro2,4-dinitrobenzene (CDNB) as substrate. GST activity was expressed in $\mu \mathrm{mol} / \mathrm{min} / \mathrm{mg}$ protein.
2.11. Protein Determination. Protein content of plasma and all fractions was estimated by the method of Lowry et al. [38] using bovine serum albumin as standard.

2.12. Histopathological Studies. The method of Baker and Silverton [39] was employed for the processing of liver for histopathological studies.

2.13. Statistical Analysis. Results were expressed as mean of 5 replicates \pm SD. Data obtained were subjected to oneway Analysis of Variance (ANOVA) and complemented with Duncan's multiple range test using Stat Pac Statistical Software. Statement of statistical significance was based on $P<0.05$.

\section{Results}

3.1. Effect of Levofloxacin Treatment on Plasma Creatinine, Urea, and Bilirubin in Rats. Table 1 shows the effect of LFX treatment on plasma creatinine, urea, and bilirubin. Plasma creatinine, urea, and bilirubin were significantly increased $(P<0.05)$ in the treated groups by $19 \%, 22 \%$, and $26 \% ; 31 \%$, $44 \%$, and $53 \% ; 100 \%, 133 \%$, and $175 \%$, respectively, relative to the control.

3.2. Effect of Levofloxacin Treatment on Plasma ALP, ALT, and AST Activities in Rats. The effect of LFX treatment on plasma ALP, ALT, and AST is presented in Table 2. Administration of different doses of LFX significantly increased the plasma activities of ALP, ALT, and AST by $18 \%, 37 \%$, and $48 \%$; $45 \%, 58 \%$, and $67 \% ; 37 \%, 43 \%$, and $57 \%$, respectively, when compared to the control.

3.3. Effect of Levofloxacin Treatments on Lipid Profiles. Table 3 represents the effect of LFX treatment on lipid profiles. Plasma total cholesterol, HDL cholesterol, LDL cholesterol, 
TABLE 3: Effects of levofloxacin treatments on plasma lipid profile in rats.

\begin{tabular}{lcccc}
\hline Treatment & Total cholesterol $(\mathrm{mg} / \mathrm{dL})$ & HDL-cholesterol $(\mathrm{mg} / \mathrm{dL})$ & LDL-cholesterol $(\mathrm{mg} / \mathrm{dL})$ & Triglyceride $(\mathrm{mg} / \mathrm{dL})$ \\
\hline Control & $68 \pm 3.30$ & $38 \pm 4.34$ & $4.5 \pm 0.5$ & $13.5 \pm 0.35$ \\
LFX-1 & $87.8 \pm 3.29(29 \%)^{*}$ & $51 \pm 2.16(34 \%)^{*}$ & $6.6 \pm 0.8(23 \%)^{*}$ & $20 \pm 1.0(54 \%)^{*}$ \\
LFX-2 & $102 \pm 2.21(50 \%)^{*}$ & $55 \pm 3.30(45 \%)^{*}$ & $7.8 \pm 0.6(56 \%)^{*}$ & $23.5 \pm 0.78(77 \%)^{*}$ \\
LFX-3 & $113 \pm 1.70(66 \%)^{*}$ & $58 \pm 3.87(53 \%)^{*}$ & $9.4 \pm 0.7(83 \%)^{*}$ & $28 \pm 1.7(115 \%)^{*}$ \\
\hline
\end{tabular}

The values are means \pm SD for five rats in each group. ${ }^{*}$ Significantly different from the control, $P<0.05$. Values in parenthesis represent percentage (\%) of the increase.

TABLE 4: Effects of levofloxacin treatments on hepatic superoxide dismutase (SOD) and catalase in rats.

\begin{tabular}{lcc}
\hline Treatment & Superoxide dismutase (Units/mg protein) & Catalase $\left(\mu \mathrm{mol} \mathrm{H}_{2} \mathrm{O}_{2}\right.$ consumed/min/mg protein) \\
\hline Control & $7.52 \pm 0.10$ & $0.63 \pm 0.01$ \\
LFX-1 & $5.8 \pm 0.23(23 \%)^{*}$ & $0.58 \pm 0.01(8 \%)^{*}$ \\
LFX-2 & $3.5 \pm 0.23(52 \%)^{*}$ & $0.49 \pm 0.03(14 \%)^{*}$ \\
LFX-3 & $2.7 \pm 0.38(66 \%)^{*}$ & $0.33 \pm 0.02(25 \%)^{*}$ \\
\hline
\end{tabular}

The values are means \pm SD for five rats in each group. ${ }^{*}$ Significantly different from the control, $P<0.05$. Values in parenthesis represent percentage (\%) of the increase.

and triglyceride levels were significantly increased by $29 \%$, $50 \%$, and $66 \% ; 34 \%, 45 \%$, and $53 \% ; 23 \%, 56 \%$, and $83 \% ; 54 \%$, $77 \%$, and $115 \%$ in all treated groups, respectively, relative to the control.

3.4. Effect of Levofloxacin Treatment on Enzymatic Antioxidants. Effect of LFX treatment on hepatic SOD and catalase is shown in Table 4. Hepatic SOD and catalase activities were significantly reduced in all the treated groups by $23 \%, 52 \%$, and $66 \% ; 8 \%, 14 \%$, and $25 \%$, respectively, when compared to control. Similarly, hepatic GST activity was significantly reduced (Figure 2) in all the treated groups by $33 \%, 50 \%$, and $57 \%$, respectively, relative to control.

3.5. Influence of Levofloxacin Treatment on Hepatic Nonenzymatic Antioxidants and Lipid Peroxidation. Figure 3 shows the hepatic vitamin $\mathrm{C}$ level following treatment with different doses of LFX. The vitamin C level was significantly decreased by $38 \%, 53 \%$, and $70 \%$ in the treated groups when compared with the control. Similarly, hepatic GSH level was decreased significantly (Figure 4) in all the treated groups by $19 \%, 38 \%$, and $60 \%$, respectively, relative to control. However, hepatic level of malondialdehyde (MDA) (Figure 5) was increased significantly in the treated groups by $15 \%, 24 \%$, and $34 \%$, respectively.

\section{Discussion}

The fluoroquinolone antibiotics have been reported to generate reactive oxygen species which may result in oxidative stress and cellular damage to the liver and kidney [40-42]. In this study, levofloxacin used at three different doses (halftherapeutic, therapeutic, and double-therapeutic) induced marked renal and hepatic damage and oxidative stress and depleted the hepatic antioxidant reserves.

Plasma ALT and AST are reliable marker enzymes of liver function and integrity [43]. When body tissue or an

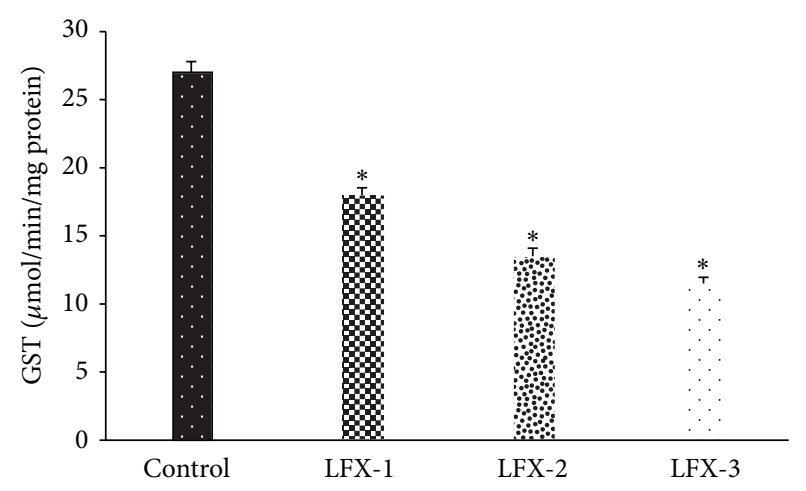

FIGURE 2: Influence of levofloxacin on hepatic glutathione-Stransferase (GST) activity in rats. The values are the means \pm SD for five rats in each group. *Significantly different from the control, $P<0.05$.

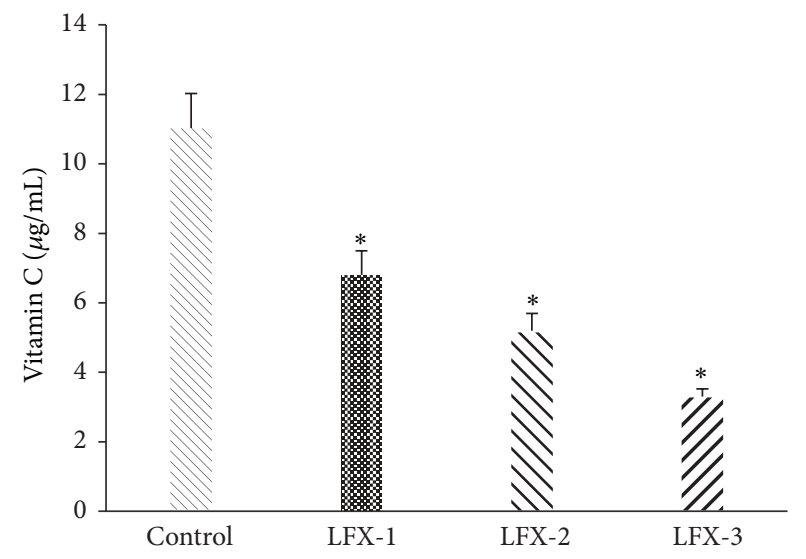

Figure 3: Influence of levofloxacin treatment on hepatic vitamin C concentration in rats. The values are the means \pm SD (range) for five rats in each group. ${ }^{*}$ Significantly different from the control, $P<0.05$. 


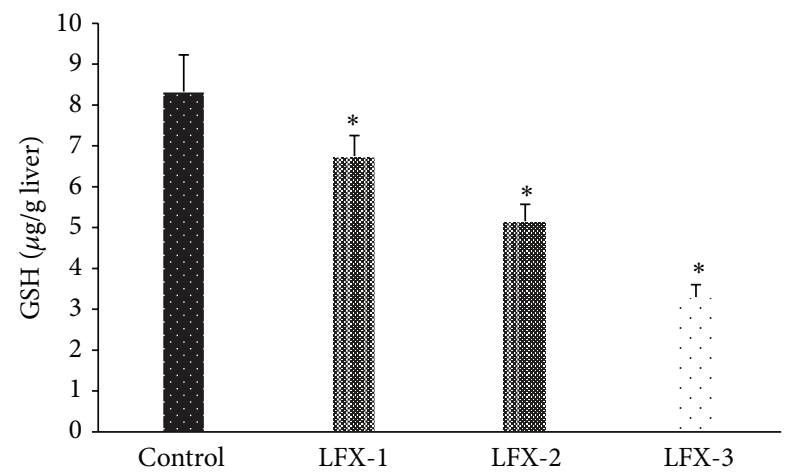

FIGURE 4: Influence of levofloxacin treatment on hepatic GSH concentration in rats. The values are the means \pm SD (range) for five rats in each group. *Significantly different from the control, $P<0.05$.

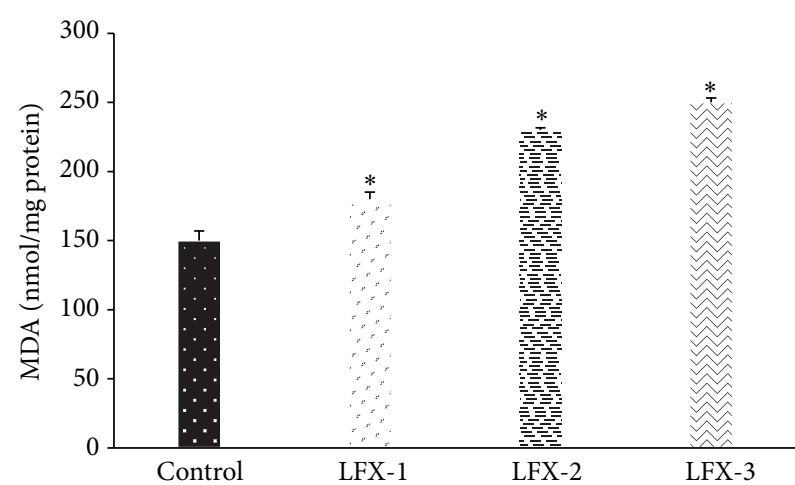

FIGURE 5: Influence of levofloxacin treatments on hepatic lipid peroxidation (MDA) level in rats. The values are the means \pm SD (range) for five rats in each group. ${ }^{*}$ Significantly different from the control, $P<0.05$.

organ such as the heart or liver is diseased or damaged, additional AST and ALT are released into the bloodstream. Increase in plasma ALT and AST has been reported in conditions involving necrosis of hepatocytes [44], myocardial cells, erythrocyte, and skeletal muscle cells [45]. Alkaline and total acid phosphatases are produced by several parts of the body especially the liver. Plasma ALP elevation has been attributed to increased osteoblastic activity such as in hyperparathyroidism, osteomalacia, and neoplasm and also in hepatobiliary diseases [45]. These enzymes, AST, ALP, and ALT, are diagnostic enzymes, and their release above normal physiological levels indicates a disease condition including various bone disorders and jaundice (ALP); viral hepatitis (ALT); and myocardial infarction (AST) [46]. The elevation in the activity of these enzymes by LFX may be as a result of their release in response to tissue damage during routine normal destruction of erythrocytes, leukocytes, and other cells like liver cells [47]. Both urea and creatinine are metabolic waste products that are freely filtered by the glomeruli of the kidneys [48]. Serum/plasma concentrations are commonly used to screen for renal or cardiovascular diseases [49]. More so, plasma urea has been reported to increase in acute and chronic intrinsic renal disease and also when there is decreased effective circulating blood volume with decreased renal perfusion [50]. Elevation of the plasma levels of creatinine and urea by LFX is an indication of abnormal renal function [51] while elevated level of bilirubin has been associated with hepatocellular damage, intraand extrahepatic biliary tract obstruction, intravascular and extracellular haemolysis, and neonatal jaundice [52].

Cells have a number of mechanisms to protect themselves from the toxic effects of ROS. These include free radical scavengers and chain reaction terminators enzymes, like glutathione (GSH), vitamins $\mathrm{C}$ and $\mathrm{E}, \mathrm{SOD}, \mathrm{CAT}$, and GSH peroxidase [53]. Inhibition of these protective mechanisms or the reduction in their activities would result in enhanced sensitivity of the cells to free radical-induced cellular damage, due to accumulation of superoxide ions and hydrogen peroxide. SOD removes superoxide ion $\left(\mathrm{O}_{2}{ }^{-}\right)$by converting it to hydrogen peroxide $\left(\mathrm{H}_{2} \mathrm{O}_{2}\right)$, which could be rapidly converted to water and oxygen by CAT [54]. SOD has a high catalytic effect, and it is present in high concentrations in all tissues, protecting cells against $\mathrm{O}_{2}{ }^{-}$under normal conditions [55]. A decrease in the activity of SOD observed in this study might increase the cell's susceptibility to attack by $\mathrm{O}_{2}{ }^{-}$. Catalase catalyzes the breakdown of $\mathrm{H}_{2} \mathrm{O}_{2}$ generated by the actions of SOD to water and $\mathrm{O}_{2}$ [56]. Therefore, the reduction in the activities of $\mathrm{CAT}$ and $\mathrm{SOD}$ by the drug may render the liver more susceptible to $\mathrm{H}_{2} \mathrm{O}_{2}$ and hydroxyl radical-induced oxidative stress. Ascorbic acid is a water soluble compound which scavenges biologically relevant free radicals, by reacting with oxygen radicals to generate semialdehyde ascorbate radical (a less reactive radical that can be scavenged by ascorbic acid). Thus, decrease in ascorbate's activity occasioned by LFX administration makes the cell more susceptible to free radicals. The level of reduced glutathione (GSH) is a measure of the cellular redox status [57]. Hence, alteration in glutathione concentration may affect the overall redox status of the cell. GST catalyzes the conjugation of reduced glutathione by conjugating these compounds (often electrophilic and somewhat lipophilic in nature) with reduced glutathione (GSH) to facilitate dissolution in the aqueous cellular and extracellular media, and, from there, out of the body. Severe oxidative stress might result in decrease in GST with concomitant depletion of glutathione [58]. Thus, decrease in GST observed from the result correlates with the depletion of GSH in the liver, confirming drug toxicity. Other researchers have reported the induction of oxidative stress and depletion of antioxidant status by fluoroquinolones $[59,60]$.

The increase in HDL-cholesterol, LDL-cholesterol, total cholesterol, and triglycerides indicates a disorder in the metabolism of lipoproteins and lipid. It has been suggested that cholesterol is a general indicator of the level of lipid in circulation [61] and the more the lipid, the greater the amount of lipid peroxidation activity and the greater the amount of lipid peroxidation products such as MDA. Increase in the level of lipid peroxidation has been described as a biomarker of tissue damage [62]. The increased hepatic lipid peroxidation as evidenced by the increased production of 
MDA in this study indicates the involvement of free radicalinduced oxidative cell injury in mediating the toxicity of fluoroquinolone. This observation is in agreement with the reports of several authors $[42,60]$.

\section{Conclusion}

Overall, our results from this study reveal that levofloxacin at different doses induced renal and liver damage and oxidative stress and altered both enzymatic and nonenzymatic antioxidant defense system in rats.

\section{Conflict of Interests}

The authors declare that there is no conflict of interests.

\section{References}

[1] C. M. Oliphant and G. M. Green, "Quinolones: a comprehensive review," The American Family Physician, vol. 65, no. 3, pp. 455464, 2002.

[2] S. Shenoy, S. Chakravarty, A. Nayak, P. Z. Candita, and T. Shanbhag, "Anxiogenic effect of moxifloxacin in wistar rats," The International Journal of Applied Biology and Pharmaceutical Technology, vol. 3, no. 4, pp. 158-162, 2011.

[3] R. H. H. Nelwan, K. C. Lie, S. Hadisaputro et al., "A singleblind randomized multicenter comparative study of efficacy and safety of levofloxacin vs ciprofloxacin in the treatment of uncomplicated typhoid fever," in Proceedings of the ASTMH 55th Annual Meeting, abstract 2517, Atlanta, Ga, USA, November 2006.

[4] H. D. Langtry and H. M. Lamb, "Levofloxacin: Its use in infections of the respiratory tract, skin, soft tissues and urinary tract," Drugs, vol. 56, no. 3, pp. 487-515, 1998.

[5] K. F. Croom and K. L. Goa, "Levofloxacin: a review of its use in the treatment of bacterial infections in the United States," Drugs, vol. 63, no. 24, pp. 2769-2802, 2003.

[6] T. Foster, "Plasmid determined resistance to antimicrobial drugs and toxic metal ions in bacteria, Levofloxacin Side Effects," Biochemistry, vol. 97564, pp. 35-65, 2009.

[7] N. Hayashi, Y. Nakata, and A. Yazaki, "New findings on the structurephototoxicity relati onship a nd photos tabili ty of fluoroquinolones with various substituents at position 1," Antimicrobial Agents and Chemotherapy, vol. 48, no. 3, pp. 799-803, 2004.

[8] B. A. Lipsky and C. A. Baker, "Fluoroquinolone toxicity profiles: a review focusing on newer agents," Clinical Infectious Diseases, vol. 28, no. 2, pp. 352-364, 1999.

[9] R. Stahlmann and H. Lode, “Toxicity of quinolones," Drugs, vol. 58, no. 2, pp. 37-42, 1999.

[10] D. C. Hooper, "Mode of action of fluoroquinolones," Drugs, vol. 58, supplement 2, pp. 6-10, 1999.

[11] J. Child, D. Mortiboy, J. M. Andrews, A. T. Chow, and R. Wise, "Open-label crossover study to determine pharmacokinetics and penetration of two dose regimens of levofloxacin into inflammatory fluid," Antimicrobial Agents and Chemotherapy, vol. 39, no. 12, pp. 2749-2751, 1995.

[12] D. N. Fish and A. T. Chow, "The clinical pharmacokinetics of levofloxacin," Clinical Pharmacokinetics, vol. 32, no. 2, pp. 101119, 1997.
[13] A. Hemeryck, R. N. V. S. Mamidi, M. Bottacini, D. Macpherson, M. Kao, and M. F. Kelley, "Pharmacokinetics, metabolism, excretion and plasma protein binding of ${ }^{14} \mathrm{C}$-levofloxacin after a single oral administration in the Rhesus monkey," Xenobiotica, vol. 36, no. 7, pp. 597-613, 2006.

[14] J. S. Wolfson and D. C. Hooper, “The fluoroquinolones: structures, mechanisms of action and resistance, and spectra of activity in vitro," Antimicrobial Agents and Chemotherapy, vol. 28, no. 4, pp. 581-586, 1985.

[15] M. L. Grayson, A. Kucers, S. M. Crowe, and J. F. Hoy, The Use of Antibiotics: A Clinical Review of Antibacterial, Antifungal, and Antiviral Drugs, The Bath Press, 1999.

[16] I. Harding and I. Simpson, "Levofloxacin: low potential for hepatobiliary adverse reactions," Clinical Bacterial Infection, vol. 7, supplement 1, p. 164, 2001, Abstract P851.

[17] L. J. Martínez, R. H. Sik, and C. F. Chignell, "Fluoroquinolone antimicrobials: singlet oxygen, superoxide and Phototoxicity," Photochemistry and Photobiology, vol. 67, no. 4, pp. 399-403, 1998.

[18] M. Goswami, S. H. Mangoli, and N. Jawali, "Involvement of reactive oxygen species in the action of ciprofloxacin against Escherichia coli," Antimicrobial Agents and Chemotherapy, vol. 50, no. 3, pp. 949-954, 2006.

[19] B. Halliwell and J. M. C. Gutteridge, "Free radical, other reactive species and disease," in Free Radicals in Biology and Medicine, pp. 617-783, Clarendon Press, 1999.

[20] S. M. Zaidi and N. Banu, "Antioxidant potential of vitamins A, $\mathrm{E}$ and $\mathrm{C}$ in modulating oxidative stress in rat brain," Clinica Chimica Acta, vol. 340, no. 1-2, pp. 229-233, 2004.

[21] B. Halliwell, "Establishing the significance and optimal intake of dietary antioxidants: the biomarker concept," Nutrition Reviews, vol. 57, no. 4, pp. 104-113, 1999.

[22] A. Y. Sun and Y. M. Chen, "Oxidative stress and neurodegenerative disorders," Journal of Biomedical Science, vol. 5, no. 6, pp. 401-414, 1998.

[23] P. M. Abuja and R. Albertini, "Methods for monitoring oxidative stress, lipid peroxidation and oxidation resistance of lipoproteins," Clinica Chimica Acta, vol. 306, no. 1-2, pp. 1-17, 2001.

[24] S. Gupta, A. Agarwal, J. Banerjee, and J. G. Alvarez, "The role of oxidative stress in spontaneous abortion and recurrent pregnancy loss: a systematic review," Obstetrical and Gynecological Survey, vol. 62, no. 5, pp. 335-347, 2007.

[25] National Research Council, Guide for the Care and Use of Laboratory Animals, The National Academies Press, National research, Washington, DC, USA, 8th edition, 2011.

[26] B. Jaffe, "What made the radical break," The New England Journal of Medicine, vol. 286, pp. 156-157, 1972.

[27] N. W. Tietz, E. L. Pruden, and O. Siggaard-Andersen, "Liver function," in Tietz Textbook of Clinical Chemistry, A. C. Burtis and E. R. Ashwood, Eds., pp. 1354-1374, WB Saunders, London, UK, 1994.

[28] N. W. Tietz, Clinical Guide to Laboratory Tests, W.B. Saunders, Philadelphia, Pa, USA, 3rd edition, 1995.

[29] M. Hørder, E. Magid, E. Pitkänen et al., "Recommended method for the determination of creatine kinase in blood modified by the inclusion of EDTA. The committee on enzymes of the Scandinavian Society for Clinical Chemistry and Clinical Physiology (SCE)," Scandinavian Journal of Clinical and Laboratory Investigation, vol. 39, no. 1, pp. 1-5, 1979. 
[30] P. Trinder, "CHOD-PAD enzymatic colorimetric method of cholesterol determination," Annals of Clinical Biochemistry, vol. 6, pp. 24-27, 1969.

[31] O. Erel, A. Kocyigit, S. Avci, N. Aktepe, and V. Bulut, "Oxidative stress and antioxidative status of plasma and erythrocytes in patients with vivax malaria," Clinical Biochemistry, vol. 30, no. 8, pp. 631-639, 1997.

[32] D. J. Jollow, J. R. Mitchell, N. Zampaglione, and J. R. Gillette, "Bromobenzene induced liver necrosis: protective role of glutathione and evidence for 3,4-bromobenzene oxide as the hepatotoxic metabolite," Pharmacology, vol. 11, no. 3, pp. 151$169,1974$.

[33] R. Varshney and R. K. Kale, "Effects of calmodulin antagonists on radiation-induced lipid peroxidation in microsomes," International Journal of Radiation Biology, vol. 58, no. 5, pp. 733-743, 1990.

[34] H. P. Misra and I. Fridovich, "The role of superoxide anion in the autoxidation of epinephrine and a simple assay for superoxide dismutase.," Journal of Biological Chemistry, vol. 247, no. 10, pp. 3170-3175, 1972.

[35] T. Magwere, Y. S. Naik, and J. A. Hasler, "Effects of chloroquine treatment on antioxidant enzymes in rat liver and kidney," Free Radical Biology and Medicine, vol. 22, no. 1-2, pp. 321-327, 1996.

[36] A. K. Sinha, "Colorimetric assay of catalase," Analytical Biochemistry, vol. 47, no. 2, pp. 389-394, 1972.

[37] W. H. Habig, M. J. Pabst, and W. B. Jakoby, "Glutathione transferases, the first enzymatic step in mercapturic acid formation," Journal of Biological Chemistry, vol. 249, no. 22, pp. 7130-7139, 1974.

[38] O. H. Lowry, N. J. Rosebrough, A. L. Farr, and R. J. Randall, "Protein measurement with the Folin phenol reagent," The Journal of Biological Chemistry, vol. 193, no. 1, pp. 265-275, 1951.

[39] F. J. Baker and R. E. Silverton, Introduction to Medical Laboratory Technology, Butter Worth, London, UK, 6th edition, 1985.

[40] V. R. Dharnidharka, K. Nadeau, C. L. Cannon, H. W. Harris, and S. Rosen, "Ciprofloxacin overdose: acute renal failure with prominent apoptotic changes," American Journal of Kidney Diseases, vol. 31, no. 4, pp. 710-712, 1998.

[41] F. Pouzaud, M. Dutot, C. Martin, M. Debray, J. M. Warnet, and P. Rat, "Age-dependent effects on redox status, oxidative stress, mitochondrial activity and toxicity induced by fluoroquinolones on primary cultures of rabbit tendon cells," Comparative Biochemistry and Physiology. Part C Toxicology and Pharmacology, vol. 143, no. 2, pp. 232-241, 2006.

[42] O. K. Afolabi and E. B. Oyewo, "Effects of ciprofloxacin and levofloxacin administration on some oxidative stress markers in the rat," International Journal of Biological, Veterinary, Agricultural and Food Engineering, vol. 8, no. 1, pp. 80-84, 2014.

[43] S. R. Naik and V. S. Panda, "Antioxidant and hepatoprotective effects of Ginkgo biloba phytosomes in carbon tetrachlorideinduced liver injury in rodents," Liver International, vol. 27, no. 3, pp. 393-399, 2007.

[44] D. S. Pratt and M. M. Kaplan, "Evaluation of abnormal liverenzyme results in asymptomatic patients," The New England Journal of Medicine, vol. 342, no. 17, pp. 1266-1271, 2000.

[45] S. K. Singh, U. Dimri, M. Kataria, and P. Kumari, "Ameliorative activity of Withania somnifera root extract on paraquat-induced oxidative stress in mice," Journal of Pharmacology and Toxicology, vol. 6, no. 4, pp. 433-439, 2011.

[46] J. B. Whitfield, "Gamma glutamyl transferase," Critical Reviews in Clinical Laboratory Sciences, vol. 38, no. 4, pp. 263-355, 2001.
[47] I. Macafarlane, A. Bomford, and R. A. Sherwood, Liver Disease and Laboratory Medicine, ACB Ventures, London, UK, 2000.

[48] D. Johnson, "CKD screening and management overview," in Handbook of Chronic Kidney Disease Management, D. John, Ed., chapter 4, Lippincott Williams \& Wilkins, 2011.

[49] M. A. Ferguson and S. S. Waikar, "Established and emerging markers of kidney function," Clinical Chemistry, vol. 58, no. 4, pp. 680-689, 2012.

[50] L. A. Stevens, J. Coresh, T. Greene, and A. S. Levey, "Assessing kidney function-measured and estimated glomerular filtration rate," The New England Journal of Medicine, vol. 354, no. 23, pp. 2473-2483, 2006.

[51] R. Mouton and K. Holder, "Laboratory tests of renal function," Anaesthesia and Intensive Care Medicine, vol. 7, no. 7, pp. 240243, 2006.

[52] Y. Nagao, H. Watanabe, and Y. Syun-ichiro, "Percentile analysis of plasma total bilirubin-how different will the rate of phototherapy for jaundice of neonates be by different standards?" Open Journal of Pediatrics, vol. 2, pp. 133-137, 2012.

[53] P. H. Proctor and J. E. McGinness, "The function of melanin.," Archives of dermatology, vol. 122, no. 5, pp. 507-508, 1986.

[54] B. Halliwell, J. M. C. Gutteridge, and C. E. Cross, "Free radicals, antioxidants, and human disease: where are we now?" The Journal of Laboratory and Clinical Medicine, vol. 119, no. 6, pp. 598-620, 1992.

[55] M. Morikawa, Y. Hirata, and T. Imanaka, "A study on the structure-function relationship of lipopeptide biosurfactants," Biochimica et Biophysica Acta, vol. 1488, no. 3, pp. 211-218, 2000.

[56] J. Čejková, S. Štípek, J. Crkovská, T. Ardan, and A. Midelfart, "Reactive oxygen species (ROS)-generating oxidases in the normal rabbit cornea and their involvement in the corneal damage evoked by UVB rays," Histology and Histopathology, vol. 16, no. 2, pp. 523-533, 2001.

[57] B. Chance, H. Sies, and A. Boveris, "Hydroperoxide metabolism in mammalian organs," Physiological Reviews, vol. 59, no. 3, pp. 527-605, 1979.

[58] Y. Aniya and A. Naito, "Oxidative stress-induced activation of microsomal glutathione $S$-transferase in isolated rat liver," Biochemical Pharmacology, vol. 45, no. 1, pp. 37-42, 1993.

[59] Ş. Altinordulu and G. Eraslan, "Effects of some quinolone antibiotics on malondialdehyde levels and catalase activity in chicks," Food and Chemical Toxicology, vol. 47, no. 11, pp. 28212823, 2009.

[60] V. Talla and P. R. Veerareddy, "Oxidative stress induced by fluoroquinolones on treatment for complicated urinary tract infections in Indian patients," Journal of Young Pharmacists, vol. 3, no. 4, pp. 304-309, 2011.

[61] D. I. Thurnham, R. Singkamani, R. Kaewichit, and K. Wongworapat, "Influence of malaria infection on peroxyl-radical trapping capacity in plasma from rural and urban Thai adults," British Journal of Nutrition, vol. 64, no. 1, pp. 257-271, 1990.

[62] J. M. C. Gutteridge, "Lipid peroxidation and antioxidants as biomarkers of tissue damage," Clinical Chemistry, vol. 41, no. 12, pp. 1819-1828, 1995. 

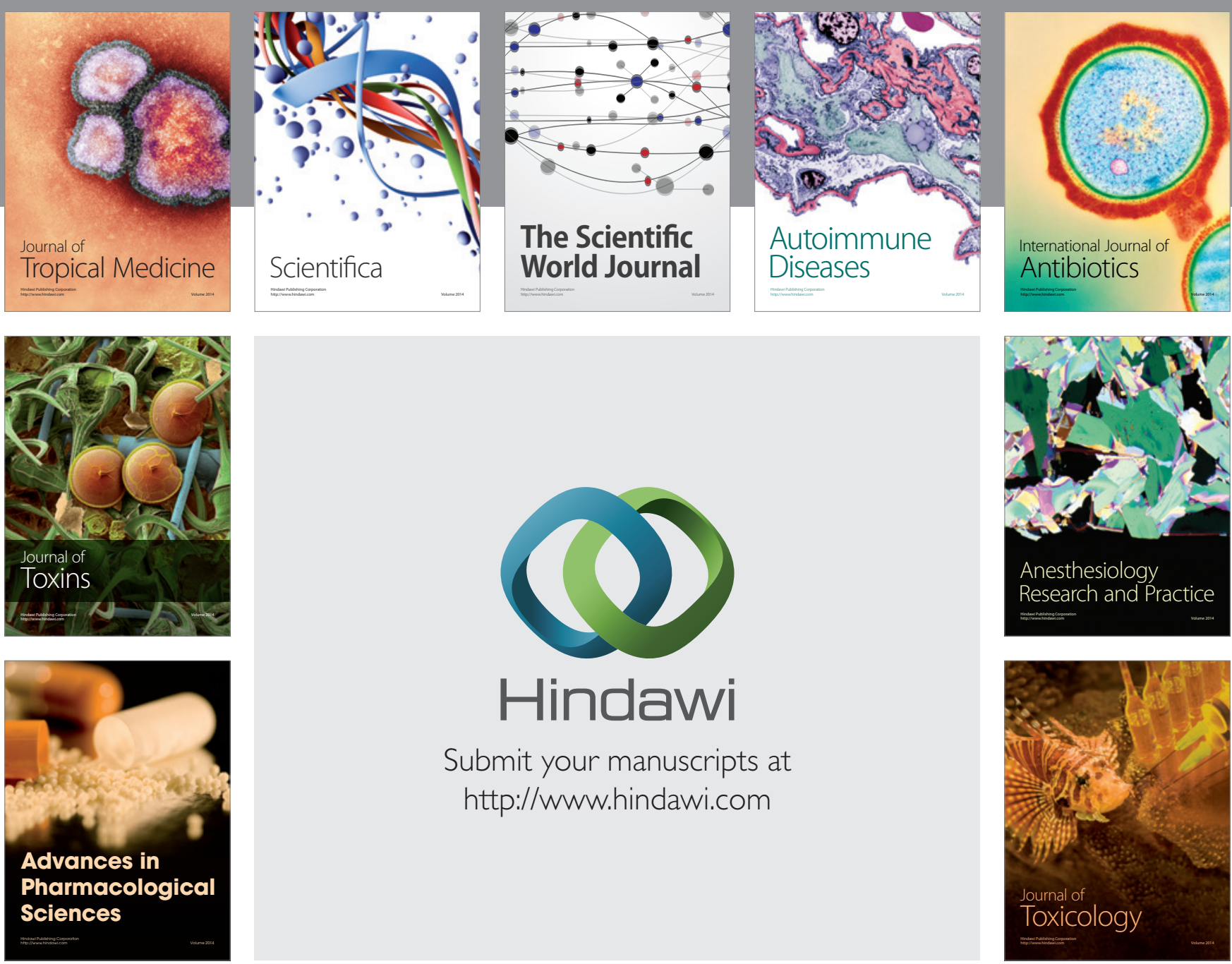

\section{Hindawi}

Submit your manuscripts at

http://www.hindawi.com
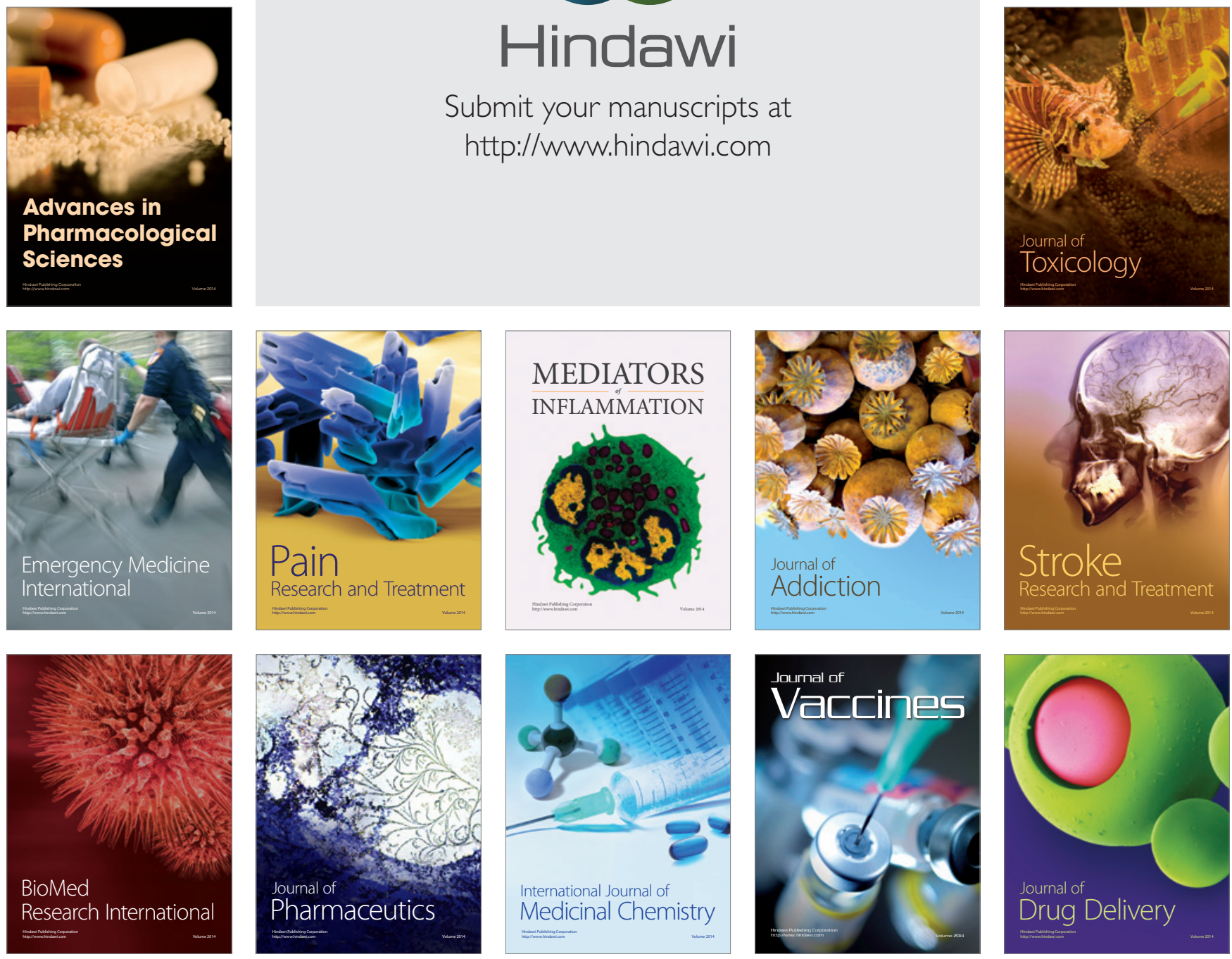